\title{
Rationale for Manufacturing of Cut-Pressed Granules from Herbal Raw Material Rich in Essential Oil: An Example of Chamomile Flowers and Sweet Flag Rhizome
}

\author{
Olga Trifonova ${ }^{1,2}$, Olga Evdokimova ${ }^{3}$, Vera Prokofieva ${ }^{4}$, Alexey Matyushin ${ }^{5, *}$
}

\section{Olga Trifonova ${ }^{1,2}$, Olga \\ Evdokimova $^{3}$, Vera \\ Prokofieva ${ }^{4}$, Alexey \\ Matyushin ${ }^{5, *}$}

'Department of Pharmacy, Sechenov First Moscow State Medical University, Moscow, RUSSIAN FEDERATION.

2JSC "Krasnogorskleksredstva", Krasnogorsk, RUSSIAN FEDERATION.

${ }^{3}$ Federal State Budgetary Institution Scientific Centre for Expert Evaluation of Medicinal Products of the Ministry of Health of the Russian Federation, Moscow, RUSSIAN FEDERATION.

${ }^{4}$ A.P. Arzamastsev Department of

Pharmaceutical and Toxicological

Chemistry, Sechenov First Moscow State

Medical University, Moscow, RUSSIAN

FEDERATION.

${ }^{5}$ Department of Analytical and Forensic Toxicology, Sechenov First Moscow State Medical University, Moscow, RUSSIAN FEDERATION.

\section{Correspondence \\ Alexey Matyushin \\ Sechenov First Moscow State Medical University, 8, Trubetskaya st., Moscow, 119991, RUSSIAN FEDERATION. \\ Phone no: +7 906-705-75-52; \\ E-mail: matyushin@sechenov.ru \\ History \\ - Submission Date: 24-07-2019; \\ - Review completed: 16-08-2019; \\ - Accepted Date: 16-08-2019.}

\section{DOI : 10.5530/pj.2019.11.199}

Article Available online

http://www.phcogj.com/v11/i6

Copyright

(C) 2019 Phcogj.Com. This is an openaccess article distributed under the terms of the Creative Commons Attribution 4.0 International license.

\begin{abstract}
Background: Currently, there are at least 43 different dosage forms present on the Russian Federation pharmaceutical market. A novel, unique dosage form - cut-pressed granules (CPG) - was developed in order to improve manufacturing characteristics and, therefore, quality of herbal drug products released in tea bags. However, treatment conditions may result in decreased levels of active substances in some of the plants, especially those containing essential oil, which is prone to degradation. The aim of this study was to assess feasibility of CPG manufacturing from herbal raw material rich in essential oil. Materials and Methods: Different morphological groups of raw material from two commonly used medicinal plants, chamomile (Matricaria recutita L.) flowers and sweet flag (Acorus calamus L.) rhizome, were chosen as the objects of the study. Qualitative composition of lipophilic constituents in herbal raw materials and CPG was assessed using thin-layer chromatography. Essential oil content was determined by steam distillation. Results: The results confirmed equivalence of chromatographic profiles for the analyzed raw materials and CPG; thus, granulation didn't affect qualitative composition of lipophilic components in chamomile flowers and sweet flag rhizome. The study also showed that the granulation process, in fact, promoted stability of the dosage form: during long-term storage the content of essential oil in all of the assessed cut-pressed granules was equivalent or higher than in corresponding herbal raw material. Conclusions: It can be concluded that Matricaria recutita L. flowers and Acorus calamus L. rhizome can be used as herbal raw material for CPG manufacturing.

Key words: Chamomile, Cut-pressed granules, Dosage form, Essential oil, Herbal drugs, Sweet flag.
\end{abstract}

\section{INTRODUCTION}

Providing access to the novel safe and effective high-quality medicinal products is the ultimate aim of the pharmaceutical industry. Although synthetic drug products and biologics remain in leading positions in key markets, products of herbal origin begin to draw more and more attention of the researchers and manufacturers. New herbal medicines can reach consumers in two ways: either by comprehensive study of various medicinal plants or by development of novel dosage forms. Currently, there are at least 43 different dosage forms present at the Russian pharmaceutical market; only some of them are actually utilized for herbal drugs. ${ }^{1}$ This justifies the necessity for interdisciplinary development of prospective dosage forms for medicinal herbal products.

Among various herbal preparations, infusions and decoctions are traditionally in well-earned favor. Optimal extraction of biologically active substances into aqueous media is influenced by several conditions, the degree of fineness being the most crucial one. Excessively large particles of herbal raw material fail to release enough active constituents, whereas exceedingly small powder contaminates extract with plant tissue particles and inert substances. Besides, herbal powders often demonstrate poor flow properties, which often hinder exact dosing on high-performance manufacturing lines. This negative factor affects most of the cut and powdered dosage forms, including herbal drugs released in tea bags; it is usually mitigated by special treatment of herbal raw material. ${ }^{2-4}$

These aspects have led to the development of a novel, unique dosage form for herbal medicinal products - cut-pressed granules (CPG). This dosage form provides better dosing accuracy and, therefore, improved consistency of aqueous infusions. Besides, it enhances mixing uniformity if the herbal raw material consists of different morphological groups (i.e., flowers, leaves, etc.). ${ }^{5-8}$

Despite obvious advantages, CPG should be manufactured only using raw material that does not degrade during processing. ${ }^{9}$ Feasibility of granulation should determined on case-by-case basis, confirming that the qualitative and quantitative composition of the material does not significantly change during processing.

Essential oils are widely used by pharmaceutical and cosmetic industry due to their pharmacological and aesthetic properties. Comprised of various lipophilic components, they are prone to degradation

Cite this article: Trifonova O, Evdokimova O, Prokofieva $V$, Matyushin A. Rationale for Manufacturing of Cut-Pressed Granules from Herbal Raw Material Rich in Essential Oil: An Example of Chamomile Flowers and Sweet Flag Rhizome. Pharmacog J. 2019;11(6):1285-9. 
during storage. ${ }^{10}$ This is also true for the herbal material containing essential oils. For example, essential oil content in chamomile significantly changes during long-term storage, decreasing by $46 \%$ during 31-month storage at $16^{\circ} \mathrm{C}$ and 60 percent relative humidity. ${ }^{11}$ Therefore, the aim of current study was to assess possibility of CPG manufacturing from two commonly used herbal raw material rich in essential oil - flowers of chamomile (Matricaria recutita L.) and rhizome of sweet flag (Acorus calamus L.), and to assess possible loss of essential oil during processing.

\section{MATERIALS AND METHODS}

Commercial batches of powdered chamomile flowers (Matricaria recutita L., flos; corresponds to the requirements of the State Pharmacopoeia ${ }^{9}$ ) and powdered sweet flag rhizome (Acorus calamus L., rhizome; corresponds to the requirements of the State Pharmacopoeia ${ }^{12}$ ) were used in the study. All chemicals used in the study were of reagent grade. Reference standards were obtained from PhytoLab (Germany).

Both types of herbal raw material were reduced to particles passing through mesh 10 sieves. After that the material was treated with saturated steam for 3-4 minutes under constant stirring. Next, moistened material was transferred into extruder and was forced though 5-7 mm aperture yielding $10-30 \mathrm{~mm}$ cylinders, which were transferred to the air dryer. After cooling, obtained cylinders were ground to granules passing through mesh 10 sieve.

Qualitative analysis of lipophilic compounds in powdered raw material and obtained CPG was performed using thin-layer chromatography (TLC) on TLC Silica gel 60 F254 plates (Merck, Germany). Samples were further grounded to particles passing through mesh 18 sieve. About $1,0 \mathrm{~g}$ of the powdered material or granules were places into a $100 \mathrm{ml}$ ground glass Erlenmeyer flask, $10 \mathrm{ml}$ of $95 \%$ ethyl alcohol were added, and the flask was heated on a boiling water bath under backflow condenser for 20 minutes. After cooling to a room temperature, the content was filtered through a paper filter, obtaining Test Solutions.

About $0.005 \mathrm{~g}$ of Sudan III reference standard (reagent grade, Ph.Eur.) were dissolved in $10 \mathrm{ml}$ of $95 \%$ ethyl alcohol, obtaining Sudan III Reference Solution.

About 0.0025 g of Sudan Red G reference standard (reagent grade, Ph.Eur.) were dissolved in $10 \mathrm{ml}$ of $95 \%$ ethyl alcohol, obtaining Sudan Red G Reference Solution.
About $0.01 \mathrm{~g}$ of menthol (reagent grade, Ph.Eur.) were dissolved in 10 $\mathrm{ml}$ of 95\% ethyl alcohol, obtaining Menthol Reference Solution

During TLC analysis of $M$. recutita flowers, $20 \mu \mathrm{l}(0.02 \mathrm{ml})$ of Test solution and $10 \mu \mathrm{l}(0.01 \mathrm{ml})$ of Sudan III Reference Solution were applied to a $100 \times 100 \mathrm{~mm}$ TLC plates as $10 \mathrm{~mm}$ bands.

In case of A. calamus rhizome, $10 \mu \mathrm{l}(0.01 \mathrm{ml})$ of Test solution and 5 $\mu \mathrm{l}(0.005 \mathrm{ml})$ of both Sudan Red G Reference Solution and Menthol Reference Solution (one over another) were applied to a $100 \times 100 \mathrm{~mm}$ TLC plates as $10 \mathrm{~mm}$ bands.

Following application, the plated were dried for $15 \mathrm{~min}$ at room temperature and placed in pre-saturated for $30 \mathrm{~min}$ TLC chambers (Camag, Switzerland) lined with filter paper. Test solutions of $M$. recutita powdered flowers and CPG were eluted using chloroform, whereas $A$. calamus rhizome Test solutions were eluted utilizing mixture of tolueneethyl acetate (95:5).

Obtained chromatograms were sprayed with Anisaldehyde Solution, which was obtained by mixing together $0,5 \mathrm{ml}$ of anisaldehyde, $10 \mathrm{ml}$ of glacial acetic acid, $85 \mathrm{ml}$ of $95 \%$ ethyl alcohol, and $5 \mathrm{ml}$ of concentrated sulfuric acid. Photographs were obtained using Reprostat 3 system (Camag, Switzerland) and processed using Adobe Photoshop 7.0 software (Adobe, USA).

The effect of granulation process on the essential oil content during long-term storage in cool, dry place away from light was assessed using conventional hydrodistillation technique. ${ }^{9}$

\section{RESULTS AND DISCUSSION}

After solvent front has passed about $80-90 \%$ of the path, the plates were removed from TLC chambers and air-dried until complete evaporation of solvent residues. Chromatograms were sprayed with Anisaldehyde Solution, heated at $105^{\circ} \mathrm{C}$ in a temperature chamber for 2-3 minutes, and examined under daylight.

Chromatographic profiles of $M$. recutita flowers powder and pilot batches of CPG are presented in Figure 1.

From the Figure 1 it can be observed that chromatographic profiles of both powdered chamomile flowers and corresponding CPG are almost identical. Thus, granulation process didn't affect qualitative composition of lipophilic compounds of $M$. recutita, suggesting that no degradation occurs during CPG manufacturing.

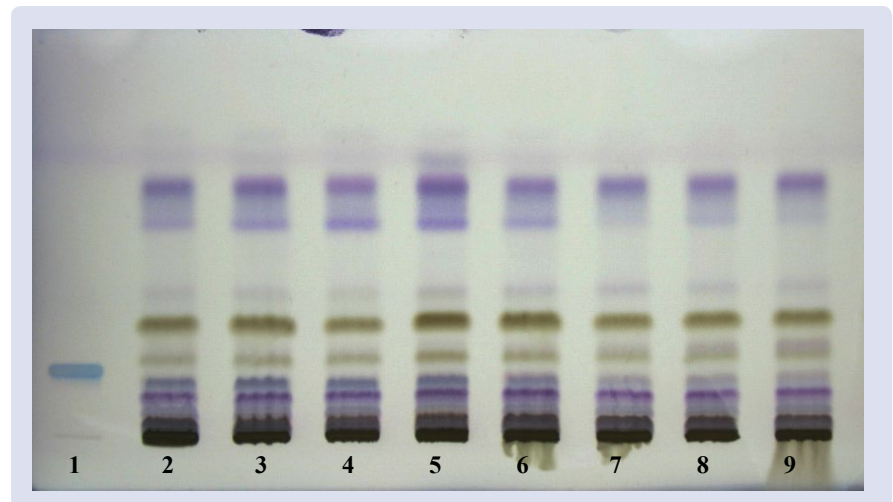

Figure 1: Chromatogram of $M$. recutita lipophilic compounds from powdered material and CPG (daylight): 1 - Sudan III Reference Solution $(10 \mu \mathrm{ll}) ; 2$ - Test solution of CPG batch No. $250418(20 \mu \mathrm{l}) ; 3$ - Test solution of CPG batch No. $280418(20 \mu \mathrm{l}) ; 4$ - Test solution of CPG batch No. 490518 $(20 \mu \mathrm{l}) ; 5$ - Test solution of CPG batch No. $480518(20 \mu \mathrm{l}) ; 6$ - Test solution of CPG batch No. $991217(20 \mu \mathrm{l}) ; 7$ - Test solution of CPG batch No. 670817 $(20 \mu l) ; 8$ - Test solution of CPG batch No. $730916(20 \mu l) ; 9$ - Test solution of CPG batch No. $250418(20 \mu l)$. 
Trifonova, et al.: Rationale for Manufacturing of Cut-Pressed Granules from Herbal Raw Material Rich in Essential Oil: An Example of Chamomile Flowers and Sweet Flag Rhizome

Chromatographic profiles of A. calamus rhizome powder and corresponding CPG are presented in Figure 2.

Similarly, no changes in qualitative composition of lipophilic compounds were observed during manufacturing of CPG from $A$. calamus rhizome.

Assessment of several pilot batches of cut-pressed granules from chamomile flowers and sweet flag rhizome showed that the essential oil content in them remained within pharmacopoeial limits (Table 1): not less than $0.3 \%$ for $M$. recutita flowers ${ }^{9}$ and not less than $2.0 \%$ for $A$. calamus rhizome. ${ }^{12}$

Essential oil content dynamics was assessed in order to provide insight into stability of manufactured CPG. The results (Tables 2 and 3) show that the granulation process, in fact, enhanced stability, as the essential oil content in CPG is equal or higher than in corresponding herbal raw material.

\section{CONCLUSION}

It was found that chromatographic profiles for the herbal raw material and corresponding cut-pressed granules were equivalent, suggesting that the granulation process does not affect qualitative composition of lipophilic constituents of $M$. recutita flowers and A. calamus rhizome.

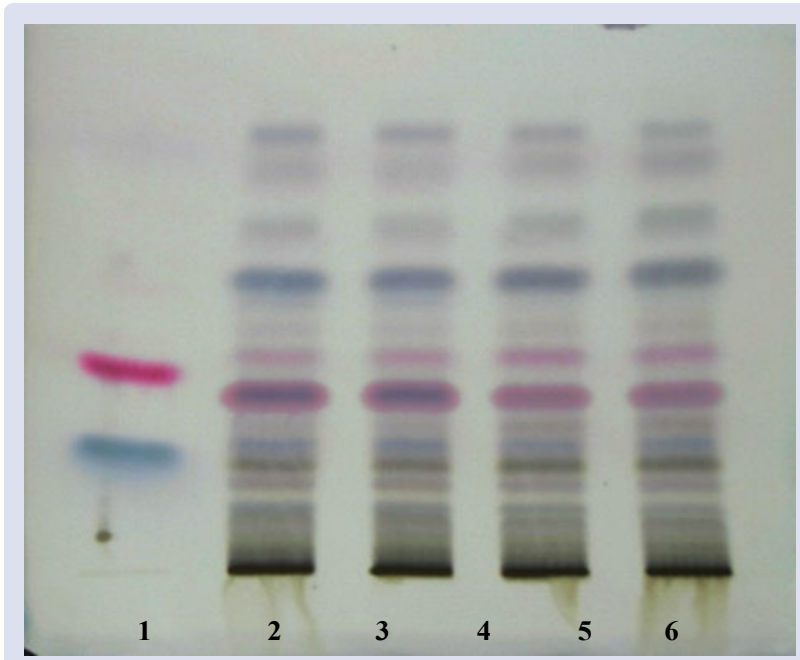

Figure 2: Chromatogram of $A$. calamus lipophilic compounds from powdered material and CPG (daylight): 1 - Sudan Red $G$ and Menthol Reference Solutions ( $5 \mu \mathrm{l}$ each); 2 - Test solution of CPG

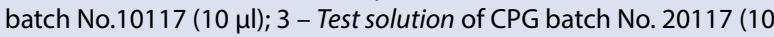
$\mu \mathrm{ll);} 4$ - Test solution of CPG batch No. $30117(10 \mu \mathrm{l}) ; 5$ - Test solution of CPG batch No. $30117(10 \mu \mathrm{l})$.

Table 1: Essential oil content in powdered $M$. recutita flowers and A. calamus rhizome, and corresponding CPG (mean of three measurements).

\begin{tabular}{|c|c|c|c|}
\hline \multicolumn{2}{|c|}{ M. recutita flowers } & \multicolumn{2}{|c|}{ M. recutita CPG } \\
\hline Batch No. & Essential oil content, \% & Sample & Essential oil content, $\%$ \\
\hline 250416 & 0.37 & CPG from batch 250416 & 0.36 \\
\hline 280416 & 0.42 & CPG from batch 280416 & 0.40 \\
\hline 490516 & 0.43 & CPG from batch 490516 & 0.42 \\
\hline 480516 & 0.44 & CPG from batch 480516 & 0.43 \\
\hline 991216 & 0.42 & CPG from batch 991216 & 0.41 \\
\hline 670816 & 0.36 & CPG from batch 670816 & 0.36 \\
\hline 730915 & 0.38 & CPG from batch 730915 & 0.37 \\
\hline \multicolumn{2}{|c|}{ A. calamus rhizome } & \multicolumn{2}{|c|}{ A. calamus CPG } \\
\hline Batch No. & Essential oil content, \% & Sample & Essential oil content, $\%$ \\
\hline 10117 & 2.4 & CPG from batch 10117 & 2.4 \\
\hline 20117 & 2.9 & CPG from batch 20117 & 2.8 \\
\hline 30117 & 2.6 & CPG from batch 30117 & 2.5 \\
\hline
\end{tabular}

Table 2: Essential oil content in M. recutita flowers and corresponding CPG following long-term storage (mean of three measurements).

\begin{tabular}{|c|c|c|c|c|c|c|c|c|}
\hline & \multirow{2}{*}{ Batch/sample } & \multicolumn{7}{|c|}{ Essential oil content, \% } \\
\hline & & Mo0 & M06 & M12 & M18 & M24 & M30 & M36 \\
\hline M. recutita flowers & 250416 & 0.37 & 0.37 & 0.36 & 0.35 & 0.35 & 0.35 & 0.33 \\
\hline M. recutita $\mathrm{CPG}$ & CPG from batch 250416 & 0.36 & 0.36 & 0.36 & 0.36 & 0.36 & 0.36 & 0.35 \\
\hline M. recutita flowers & 280416 & 0.42 & 0.42 & 0.38 & 0.36 & 0.36 & 0.36 & 0.36 \\
\hline M. recutita $\mathrm{CPG}$ & CPG from batch 280416 & 0.40 & 0.40 & 0.38 & 0.38 & 0.38 & 0.37 & 0.38 \\
\hline M. recutita flowers & 490516 & 0.43 & 0.43 & 0.36 & 0.36 & 0.35 & 0.35 & 0.36 \\
\hline M. recutita CPG & CPG from batch 490516 & 0.42 & 0.42 & 0.40 & 0.38 & 0.38 & 0.36 & 0.36 \\
\hline M. recutita flowers & 480516 & 0.44 & 0.44 & 0.36 & 0.36 & 0.37 & 0.36 & 0.36 \\
\hline M. recutita $\mathrm{CPG}$ & CPG from batch 480516 & 0.43 & 0.43 & 0.40 & 0.40 & 0.38 & 0.38 & 0.36 \\
\hline M. recutita flowers & 991216 & 0.42 & 0.42 & 0.36 & 0.36 & 0.35 & 0.36 & 0.36 \\
\hline M. recutita $\mathrm{CPG}$ & CPG from batch 991216 & 0.41 & 0.41 & 0.39 & 0.38 & 0.38 & 0.36 & 0.36 \\
\hline M. recutita flowers & 670816 & 0.36 & 0.36 & 0.35 & 0.35 & 0.35 & 0.35 & 0.33 \\
\hline M. recutita CPG & CPG from batch 670816 & 0.36 & 0.36 & 0.36 & 0.36 & 0.36 & 0.36 & 0.36 \\
\hline M. recutita flowers & 730915 & 0.38 & 0.38 & 0.35 & 0.36 & 0.35 & 0.35 & 0.35 \\
\hline M. recutita $\mathrm{CPG}$ & CPG from batch 730915 & 0.37 & 0.37 & 0.36 & 0.36 & 0.36 & 0.36 & 0.36 \\
\hline
\end{tabular}

Note: $\mathrm{M}$ - months. 
Trifonova, et al:: Rationale for Manufacturing of Cut-Pressed Granules from Herbal Raw Material Rich in Essential Oil: An Example of Chamomile Flowers and Sweet Flag Rhizome

Table 3: Essential oil content in A. calamus rhizome and corresponding CPG following long-term storage (mean of three measurements).

\begin{tabular}{|c|c|c|c|c|c|}
\hline & \multirow{2}{*}{ Batch/sample } & \multicolumn{4}{|c|}{ Essential oil content, \% } \\
\hline & & MOO & M06 & M12 & M18 \\
\hline A. calamus rhizome & 10117 & 2.4 & 2.2 & 2.2 & 2.2 \\
\hline A. calamus $\mathrm{CPG}$ & CPG from batch 10117 & 2.4 & 2.3 & 2.2 & 2.3 \\
\hline A. calamus rhizome & 20117 & 2.9 & 2.3 & 2.3 & 2.3 \\
\hline A. calamus $\mathrm{CPG}$ & CPG from batch 20117 & 2.8 & 2.5 & 2.4 & 2.4 \\
\hline A. calamus rhizome & 30117 & 2.6 & 2.4 & 2.3 & 2.2 \\
\hline A. calamus $\mathrm{CPG}$ & CPG from batch 30117 & 2.5 & 2.3 & 2.3 & 2.3 \\
\hline
\end{tabular}

Note: $\mathrm{M}$ - months.

Moreover, it was found that the granulation process had no negative impact on the essential oil content of the studied herbal material. In fact, cut-pressed granules were found to be more stable in terms of essential oil content during long-term storage.

\section{CONFLICTS OF INTEREST}

The authors declare no conflicts of interest.

\section{ABBREVIATIONS}

CPG: Cut-pressed granules; TLC: Thin-layer chromatography.

\section{REFERENCES}

1. Sakanyan El, Shemeryankina TB, Lyakina MN, Rukavitsyna NP. Current issues of standardization of herbal substances and herbal medicinal products in the Russian Federation and in the Eurasian Economic Union. Collection of scientific papers of the International Research to Practice Conference Devoted to the 85 $5^{\text {th }}$ Anniversary of VILAR. 2016 June 25-26; Moscow, Russian Federation.

2. Evdokimova OV, Stryapushkin PA, Stulovskiy SS, Semionova MV. Cut and Pressed Raw Nettle and St. John's Wort as a New Product Type. Materials of the XIV Russian National Congress "Man and Medicine". 2007 Apr 16-20; Moscow, Russian Federation.

3. Rukavitsyna NP, Antonova NP, Sakanyan El, Shemeryankina TB, Lyakina MN Modern Approaches to the quality standardisation of medicinal products and herbal medicines in terms of granulation and impurities. Collection of Research Papers of the International Conference "Biological Characteristics of Medicinal and Aromatic Plants and Their Role in Medicine. 2016 June 23-24; Moscow, Russian Federation.

4. Tskhai EV, Evdokimova OV, Devyatkina IA, Stryapushkin PA, Stulovskiy SS Study of a new product type - Nettle Leaves, Cut and Pressed. Proceedings of Voronezh State University. Chemistry Biology Pharmacy. 2007;2:191-6.

5. Trifonova OB, Evdokimova OV, Sakanyan El, Bichenova KA. Pharmaceutical analysis and quality control of drugs granules cut-extruded - new dosage form Journal of Pharmaceutical Quality Assurance Issue. 2015;1 (6):11-3.

6. Sakanyan El, Rukavitsyna NP, Evdokimova OV. Cut-pressed granules: a dosage form. Eurasian Union of Scientists. 2016;4-5(25):106-9.

7. Evdokimova OV, Sakanyan El, Trifonova OB, Sukhanova LV, Bichenova KA Rukavitsyna NP. Standardization of new dosage forms - plant granules (cutextruded). Reviews on Clinical Pharmacology and Drug Therapy. 2014;12:18.

8. Trifonova OB, Evdokimova OV, Sakanyan El, Lapkina OY, Bichenova KA Rukavitsyna NP. New dosage form - plant granules (cut-extruded). Reviews on clinical pharmacology and drug therapy. 2014;12:18.

9. The State Pharmacopoeia of the Russian Federation, 13th ed. Moscow [updated 2016; cited 20 July 2019] Available from: http://www.femb.ru/feml.

10. Turek C, Stintzing FC. Stability of essential oils: a review. Comprehensive Reviews in Food Science and Food Safety. 2013;1(12):40-53.

11. Letchamo W. Effect of storage temperatures and duration on the essential oil and flavonoids of chamomile. Journal of Herbs, Spices \& Medicinal Plants. 1993;1(3):13-26.

12. USSR State Pharmacopoeia, XI ed., Vol. 2. Moscow: Medicine, 1990, pp. 400.

\section{GRAPHICAL ABSTRACT}
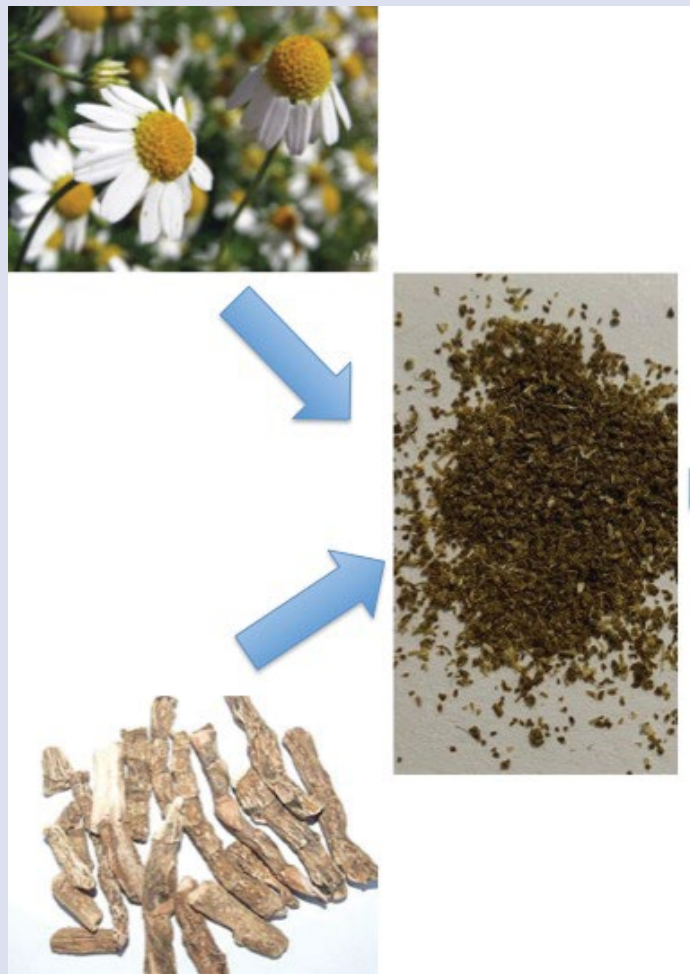
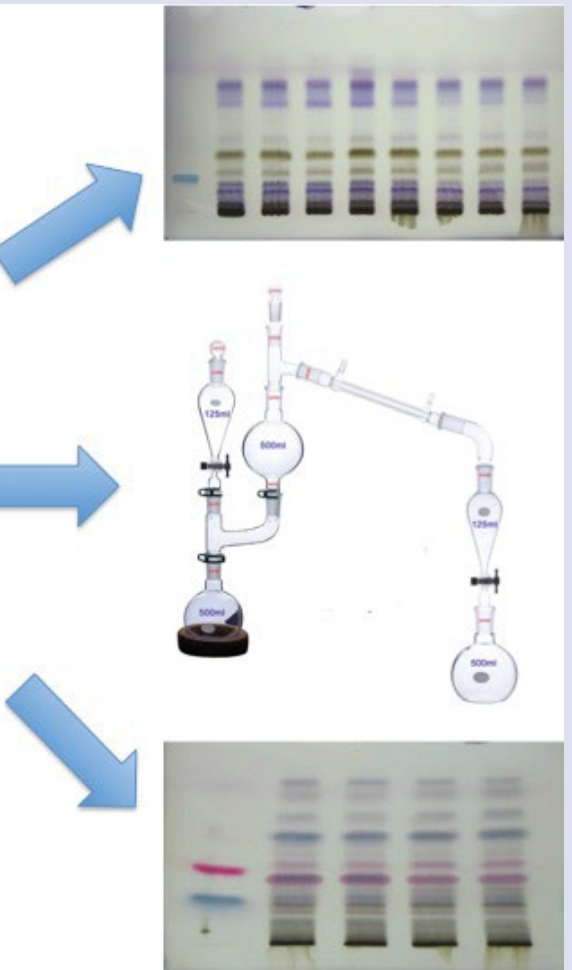


\section{ABOUT AUTHORS}

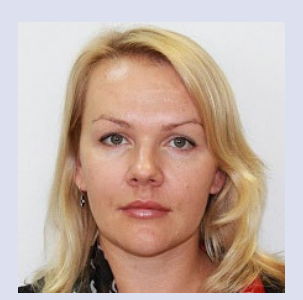

Olga B. Trifonova, a member of the Council for State Pharmacopoeia, graduated from Pharmaceutical Faculty of the Sechenov First Moscow State Medical Institute in 1998 and finished her PhD research in 2018. Since 1999 she is working at the "Krasnogorskleksredsta" - an oldest manufacturer of herbal medicinal products in the Russian Federation. Currently she holds the position of the Director for Quality and Development. Her scientific interests are focused on pharmaceutical analysis and resource-saving technologies in herbal drugs manufacturing.

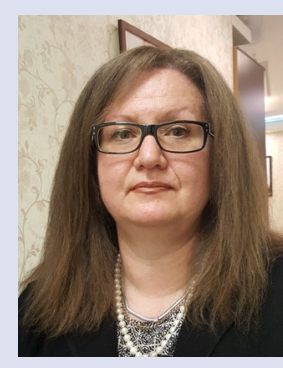

OlgaV. Evdokimova, a member of the Council for State Pharmacopoeia, graduated from Pharmaceutical Faculty of the Sechenov First Moscow State Medical Institute in 1989, earned her PhD degree in 1996, and her D.Sc.Pharm degree - in 2012. Since 2018 she works as the Chief Analyst of the Center of Pharmacopoeia and International Collaboration of the FSBI "Scientific Center for Expert Evaluation of Medicinal Products." Her scientific interests are focused on development and standardization of herbal raw material, herbal drugs, and herbal food supplements.

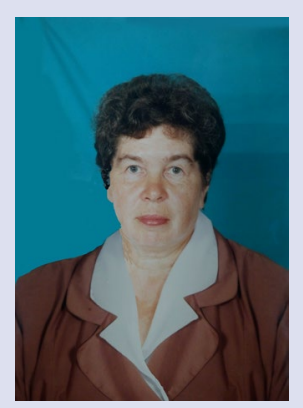

Vera I. Prokofieva, a member of the Council for State Pharmacopoeia, graduated from Pharmaceutical Faculty of the Sechenov First Moscow State Medical Institute in 1966, obtained her PhD degree in 1969, and her D.Sc.Pharm. degree - in 1989. Since 1990 she works as the professor of the A.P. Arzamastsev Deparment of Pharmaceutical and Toxicological Chemistry. Her scientific interests are focused on pharmaceutical analysis of drug substances by spectral and chromatographic methods.

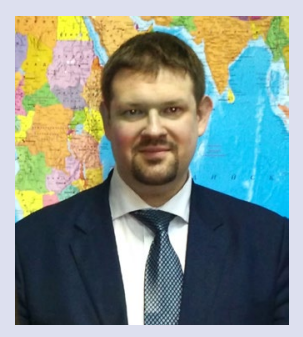

Alexey A. Matyushin graduated from Pharmaceutical Faculty of the Sechenov First Moscow State Medical Academy in 2008, earned his PhD degree in 2011, and MA degree - in 2018. Currently he's working as the Associate Professor of the Department of Analytical and Forensic Toxicology. His main scientific interests are focused on identification and standardization of novel herbal drugs and herbal raw materials, separation and purification of biologically active substances from natural sources, and herbal drugs development.

Cite this article: Trifonova O, Evdokimova O, Prokofieva V, Matyushin A. Rationale for Manufacturing of Cut-Pressed Granules from Herbal Raw Material Rich in Essential Oil: An Example of Chamomile Flowers and Sweet Flag Rhizome. Pharmacog J. 2019;11(6):1285-9. 